\title{
THE ALDRICH PLAN: A POSSIBLE MONETARY GERRYMANDER ${ }^{\mathrm{x}}$
}

With a gathering such as this it is unnecessary to take much time in the preliminary presentation of a currency argument because most of us understand pretty well the failings of our present system. But because of the different ways of phrasing the trouble and because I want to establish a premise upon which to work I must take a little time to place before you my understanding of the economic cause of the failure of our present banking machinery. This is more necessary because I believe that any speaker for the negative does only half his work when he tears down the ideas of the supporter of any question, leaving only a mass of antagonistic argument without any suggested reconstruction.

Under our present system by far the greatest part of our circulating medium is no longer a government promise to pay-a hand-to-hand, hard money. About. $9 \circ$ per cent of our business is transacted by a comparatively new money, check transfer of bank credit. The volume of this new money is very elastic and the clearing-house reports show how closely it fluctuates in accord with business activity, or the money demand. Therefore we may justly claim that about 90 per cent of our circulating money is already almost ideally elastic.

If we analyze the combined statement of our whole banking system we see at once that two items bear a distinct relation to each other: the loans, on the asset side, and the deposits, on the liability side. This is the endless chain of our banking machinery. Loans made, in the whole scheme, create deposits; and the expansion or contraction of one is followed by an expansion or contraction of the other. Now the important thing to remember in this connection is that when a bank, a group of banks, or a whole banking system comes before us for its last analysis, we find that a demand liability has been created in exchange for a comparatively

I A paper read before the Western Economic Association at Chicago, November II, I9Ir. 
long-time asset. The depositors have been given a right to demand an immediate cash payment in return for which they, as a body, have given the banks their paper maturing in thirty, sixty, or ninety days, or even longer maturities. Any student of commercial credit in analyzing any statement knows that there must be a reasonable ratio between quick liabilities and quick assets. In his world, thirty-, sixty-, or ninety-day paper is a quick asset, if good; but who would dare call it quick as compared to the immediate needs of a bank for currency during financial panic? While the vast number of bank depositors are content to use checks in their business operations most of the time, there come times of doubt when these same depositors revert to a desire for government money. They want the hard cash. This unrest is due to an undefined and indefinite doubt as to the ability of the banks to make cash payments as freely as demanded. Fortunately this dread is not generally long lived, and when they become convinced that they can really get a hard-cash money freely their desire for the same ordinarily abates.

Now what this system of ours needs is some equalizing mechanism that will tend to restore the monetary balance between quick assets and quick liabilities in time of stress. What we really want is some way of using the comparatively long-time assets of our banking system by some elastic temporary transfer into a handto-hand bearer money of unquestioned value and acceptability. The need for some method of accomplishing this is what first prompted the Aldrich-Vreeland Bill and then resulted in the creation of the National Monetary Commission; and if this can be brought about we shall need little else to alleviate our monetary crop-moving stringencies or panic conditions due at present to the inability of our banks to supply a hand-to-hand money at times of extraordinary demand.

Almost all students of finance are agreed that there must be some central source from which this elasticity may be secured. The central-bank plan has time and again been advanced as the scientific solution of the difficulty. But the people of this country rightly demand that any such plan must first provide clearly three things: First, this central mechanism must be absolutely beyond 
the control of selfish financial interests. Second, every part of the country must receive impartial assistance in time of financial stress. Third, it must be clearly shown that the mechanism of the plan is so designed that it will develop automatically with the changing economic conditions of the country entirely independent of any prearranged board of control.

Now, with this in mind (and I think you will agree with me that this premise is a safe one to stand on), I wish to analyze two features of the plan of Mr. Aldrich that in my opinion do not measure up to the standard that should be rigidly required of any plan so vastly different from what we now have. These particular features are those referring to the fifteen districts and the directors of the Reserve Association. In the original plan fifteen districts were mentioned and no provision was made for any change to accommodate the country's economic growth. This has been remedied to a certain extent by arranging to allow the directors to increase the number of districts. But no mention is made of where the original fifteen districts will be or how they will be selected. We have only one thing to guide us in estimating what these districts may be and that is the logical analysis of the rest of the plan. All through this scheme we find that directors of local associations and the district associations and the central association are elected in two ways, one senatorial and the other representative. This representative plan is so prominent throughout the bill that we must perforce believe that each district must contain about the same amount of bank capital in order to have the banks fairly represented on the central board.

Senate document No. 225, for the Sixty-first Congress, second session, being a set of charts issued by the monetary commission, gives on p. I7 the total capital of all banks reporting as of April 28 , 1909, as $\$ 1,793,984,325.00$. I use these figures because it is presumably from these statistics that Senator Aldrich formulated his report. If we are correct, then, in our logic, each district must contain at first one-fifteenth of the total bank capital, which would be $\$ 119,598,955$. We may then use $\$ 119,500,000$ as a unit in attempting to ascertain the general disposition of the fifteen districts. 
In its charts of banking conditions the commission has used six main divisions of the country; namely, New England, eastern states, southern states, middle western states, western states, and Pacific states. In round figures the total banking capital of this country is divided among these groups about as follows:

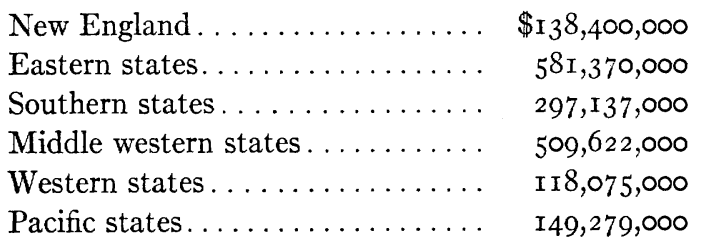

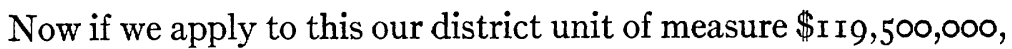
we shall ascertain how many districts should logically be in each of the foregoing geographical divisions of the country. This would result in the following:

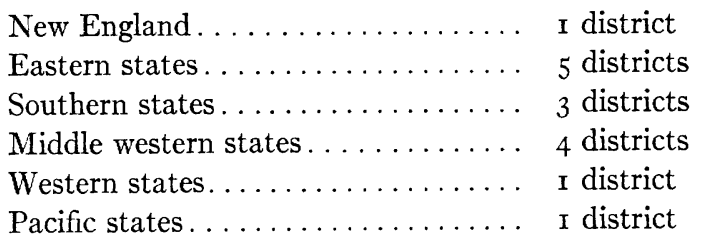

With this as the logical districting in mind I now wish to turn to that part of the plan relating to the directors of the Reserve Association. Here we find first six ex-officio members who are not directly regulated by the district plan. Second, in Section I5, we find an additional fifteen directors, one from each district on the senatorial basis. This would result in the various divisions having directors as follows:

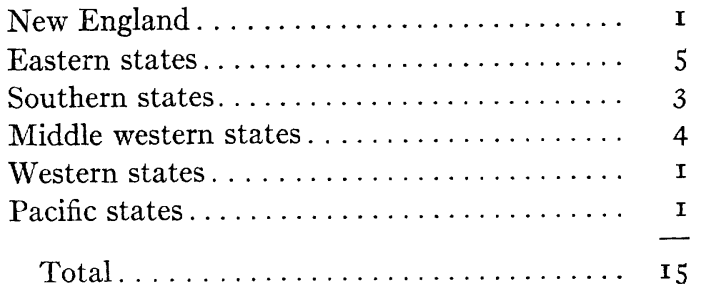

The third subdivision of this general article, Section 16 of the bill, calls for twelve additional directors elected by voting representatives of the various districts, each representative casting a number 
of votes equal to the number of shares in the National Reserve Association held by the banks in his district. As the number of shares held by any bank is in direct proportion to its capital stock, a comparison of the stock in the various geographic divisions already mentioned will show their proportionate vote and the percentage of these twelve directors that would be elected from that part of the country. We must of course adjust the fractions, and the following table represents the percentage of capital in one section to the whole country's capital, and the number of directors that would be elected under this section of the bill from the geographic sections of the country.

\begin{tabular}{|c|c|c|}
\hline & $\begin{array}{l}\text { Percentage } \\
\text { of Capital }\end{array}$ & $\begin{array}{l}\text { No. of } \\
\text { Directors }\end{array}$ \\
\hline 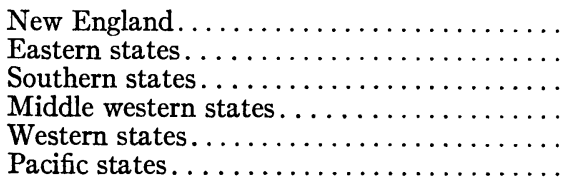 & $\begin{array}{r}8 \\
32 \\
17 \\
28 \\
7 \\
8\end{array}$ & $\begin{array}{l}\text { I } \\
4 \\
2 \\
3 \\
\text { I } \\
\text { I }\end{array}$ \\
\hline Total.... & 100 & I 2 \\
\hline
\end{tabular}

The fourth division of this article, Section 17 of the bill, calls for an additional twelve directors elected by the board so far provided for. It is fair to presume that in this selection the ordinary laws of nature will work out and that of these twelve to be elected the proportion from the various sections of the country will be about the same as that represented by the members already elected. The following table gives the number of directors elected under Sections 15 and 16 , the percentage of directors already

\begin{tabular}{|c|c|c|c|}
\hline & $\begin{array}{c}\text { Elected } \\
\text { under } \\
\text { Sections } \\
\text { r5 and } \mathbf{6} 6\end{array}$ & $\begin{array}{l}\text { Percentage } \\
\text { So Far }\end{array}$ & $\begin{array}{c}\text { No. of } \\
\text { Directors } \\
\text { Probable } \\
\text { under Sec- } \\
\text { tion } 17\end{array}$ \\
\hline 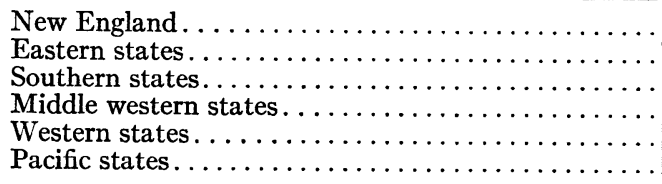 & $\begin{array}{l}2 \\
9 \\
5 \\
7 \\
2 \\
2\end{array}$ & $\begin{array}{r}7 \\
33 \\
19 \\
26 \\
8 \\
7\end{array}$ & $\begin{array}{l}\text { I } \\
4 \\
2 \\
3 \\
\text { I } \\
\text { I }\end{array}$ \\
\hline 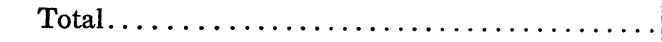 & 27 & 100 & I2 \\
\hline
\end{tabular}


elected, and the number of directors that would logically come from the various geographic sections of the country under Section $\mathrm{I} 7$, now under consideration.

A combination of these tables will show that the board would be made up of directors in the following proportion from the various geographic divisions of the country:

New England .................... 3

Eastern states ................. I3

Southern states................... 7

Middle western states............... Io

Western states.................... 3

Pacific states...................... 3

Total ......................... 39

Ex-officio members.................. 6

Total for board ................. 45

Now the main objection, in the minds of the people, against any central bank, has been due to fear of a control of the direction and policy of that bank by one class of business interest. The people are afraid that the speculative interests of the money centers and of New York in particular will be able to dominate any central organization. The very elaborate organization plan of Senator Aldrich has been very widely advertised as a sure preventive of this condition. The analysis just made indicates, if there is any weight to be attached to a logical analysis of his plan, that onethird of the elected directors must at first come from the eastern states. The second monetary center of the country lies in the Middle West and the speculative interests have nearly as complete a control here as they have in New York. The eastern and middle western states have a clear majority of the board of directors and we may rest assured that they would use every bit of latitude allowed them to direct the power of this central bankers' bank, for that is in truth all Senator Aldrich's Central Reserve Association is, so as to serve the interests of their invested capital.

Now it is quite possible, indeed the revised suggestions indicate that it is very probable, that the districts will not be designated exactly as supposed in the foregoing argument. This indication lies in Section I8 which states: "Not more than three of the 
directors elected under paragraphs $\mathrm{I} 6$ and $\mathrm{I} 7$ shall be chosen from one district." This refers to the twenty-seven directors chosen on the stock-representative basis, and was not in the original bill. It would seem to me to be put in so as to insure the impossibility of the stock-representative votes of the monetary centers losing their weight. You can see that it is no longer necessary to have the actual districts located in or touching the monetary centers, as it is clearly stated that three directors can be elected from one district, a thing which by the ambiguity of the first phrasing was tacitly understood to be impossible.

Now the main plea of the commission has been to keep the consideration of this question on a non-partisan, unpolitical basis. To do this, when the time for political activity and election comes, we must have an absolutely non-partisan and unpolitical measure for the people's consideration-a measure that neither party need fear and both can support. I am afraid that the plan under consideration will be considered as an attempt to concentrate the whole banking reserve of the country and place it under the direction of a comparatively small board of control. The movement of public sentiment in this country is at present absolutely set against any centralization of power in any industry and will surely be set against any centralization of financial power.

After this you have a right to ask me if we can suggest to the people a non-partisan, unpolitical, unconcentrated plan. I firmly believe we can suggest such a plan, and one that we have tried and found workable. So far this country has developed its currency scheme by a system of compromises until we have the hodge-podge, inelastic money of today. But this very condition has helped develop our wonderfully elastic check currency. This is our chief medium of exchange, and over it we have developed a most perfect system of control-the local clearing-house. Why do we need to go farther than the panic of 1907 to find a way of meeting and preventing stringency and monetary panic? Surely there can be no question that the potential power of our clearing-house system, used at that time- used illegally perhaps, but used in a thoroughly American manner-solved the question of monetizing our assets for a time long enough to satisfy the public and calm the panic conditions. 
Now I believe we should not look the gift horse in the face and turn away. I believe we have developed a machinery to suit our needs which, with a little adapting and organizing, can be made an instrument thoroughly well suited to our needs and absolutely beyond any possibility of sectional, capitalistic, or political control. I do not believe it is necessary or advisable to build up some entirely new machine with none of its joints tested, even if England, France, and Germany use a somewhat similar thing. I believe our system has developed our own remedy and that it stands ready to our hand waiting adoption. Of course it needs some development and adaptation. I wish I had time to explain how simply this could be accomplished.

MilwaukeE, Wis.

AleXANDER WALL 